\title{
Transmission of prices and price volatility in Australian electricity spot markets: A multivariate GARCH analysis
}

\author{
Andrew Worthington ${ }^{*}$, Adam Kay-Spratley, Helen Higgs \\ School of Economics and Finance, Queensland University of Technology, \\ GPO Box 2434, Brisbane, QLD 4001, Australia
}

\begin{abstract}
This paper examines the transmission of spot electricity prices and price volatility among the five regional electricity markets in the Australian National Electricity Market (NEM): namely, New South Wales (NSW), Queensland (QLD), South Australia (SA), the Snowy Mountains Hydroelectric Scheme (SNO) and Victoria (VIC). A multivariate generalised autoregressive conditional heteroskedasticity (MGARCH) model is used to identify the source and magnitude of price and price volatility spillovers. The results indicate the presence of positive own mean spillovers in only a small number of markets and no mean spillovers between any of the markets. This appears to be directly related to the physical transfer limitations of the present system of regional interconnection. Nevertheless, the large number of significant own-volatility and cross-volatility spillovers in all five markets indicates the presence of strong ARCH and GARCH effects. This indicates that shocks in some markets will affect price volatility in others. Finally, and contrary to evidence from studies in North American electricity markets, the results also indicate that Australian electricity spot prices are stationary.
\end{abstract}

JEL classifications: C32. C51, L94, Q40

Keywords: spot electricity price markets; mean and volatility spillovers; multivariate GARCH

\section{Introduction}

The Australian National Electricity Market (NEM) was established on 13 December 1998. It currently comprises four state-based [New South Wales, Victoria, Queensland and South Australia] and one non-state based [Snowy Mountains Hydroelectric Scheme] regional markets operating as a nationally interconnected grid. Within this grid, the largest generation capacity is found in New South Wales, followed by Queensland, Victoria, the Snowy Mountains Hydroelectric Scheme and South Australia, while electricity demand is highest in New South Wales, followed by Victoria, Queensland and South Australia. The more than seventy registered participants in the NEM, encompassing privately and publicly owned generators, transmission and distribution network providers and traders, currently supply

\footnotetext{
* Corresponding author. Tel: +61-7-3864-2658; fax: 61-703864-1500.E-mail: a.worthington@qut.edu.au.
} 
electricity to 7.7 million customers with more than $\$ 8$ billion of energy traded annually [for details of the NEM's regulatory background, institutions and operations see NEMMCO (2001, 2002), ACCC (2000) and IEA (2001)].

Historically, the very gradual move to an integrated national system was predated by substantial reforms on a state-by-state basis, including the unbundling of generation, transmission and distribution and the commercialization and privatization of the new electricity companies, along with the establishment of the wholesale electricity spot markets (Dickson and Warr, 2000). Each state in the NEM initially developed its own generation, transmission and distribution network and linked it to another state's system via interconnector transmission lines. However, each state's network was (and still is) characterised by a very small number of participants and sizeable differences in electricity prices were found. The foremost objective in establishing the NEM was then to provide a nationally integrated and efficient electricity market, with a view to limiting the market power of generators in the separate regional markets [for the analysis of market power in electricity markets see Brennan and Melanie (1998), Joskow and Kahn (2002), Wilson (2002) and Robinson and Baniak (2002)].

However, a defining characteristic of the NEM is the limitations of physical transfer capacity. Queensland has two interconnectors that together can import and export to and from NSW, NSW can export to and from the Snowy and Victoria can import from the Snowy and South Australia and export to the Snowy and to South Australia. There is currently no direct connector between NSW and South Australia (though one is proposed) and Queensland is only directly connected to NSW. As a result, the NEM itself is not yet strongly integrated with interstate trade representing just seven percent of total generation. During periods of peak demand, the interconnectors become congested and the NEM separates into its regions, promoting price differences across markets and exacerbating reliability problems and the market power of regional utilities (IEA, 2001; ACCC, 2000; NEMMCO, 2002).

While the appropriate regulatory and commercial mechanisms do exist for the creation of an efficient national market, and these are expected to have an impact on the price of electricity in each jurisdiction, it is argued that the complete integration of the separate regional electricity markets has not yet been realised. In particular, the limitations of the interconnectors between the member jurisdictions suggest that, for the most part, the regional spot markets are relatively isolated. Nevertheless, the Victorian electricity crisis of February 2000 is just one of several shocks in the Australian market that suggests spot electricity pricing and volatility in each regional market are still potentially dependent on pricing 
conditions in other markets. These are, of course, concerns that are likely to be just as important in any other national or sub-national electricity market comprised of interconnected regions.

In the United States, for example, De Vany and Walls (1999a) used cointegration analysis to test for price convergence in regional markets in the US Western Electricity Grid. On the whole the findings were suggestive of an efficient and stable wholesale power market, though De Vany and Walls (1999a) argued that the lack of cointegration in some markets provided evidence of the impact of transfer constraints within the grid. Later, De Vany and Walls used vector autoregressive modelling techniques and variance decomposition analysis to examine a smaller set of these regional markets. They concluded “...the efficiency of power pricing on the western transmission grid is testimony to the ability of decentralised markets and local arbitrage to produce a global pattern of nearly uniform prices over a complex and decentralised transmission network spanning vast distances” (De Vany and Walls 1999b: 139).

Unfortunately, no comparable evidence exists concerning the interconnected regional electricity markets in Australia, or indeed elsewhere outside the United States for that matter. This is important for two reasons. First, unlike the US the Australian NEM represents the polar case of a centrally coordinated and regulated national market. It is therefore likely to throw light on the efficiency of pricing and the impact of interconnection within centralised markets still primarily composed of commercialised and corporatised public sector entities. Second, a fuller understanding of the pricing relationships between these markets will enable the benefits of interconnection to be assessed as a step towards the fuller integration of the regional electricity markets into a national electricity market. This provides policy inputs into both the construction of new interconnectors and guidelines for the reform of existing market mechanisms.

At the same time, the manner in which volatility shocks in regional electricity markets are transmitted across time arouses interest in modelling the dynamics of the price volatility process. This calls for the application of autoregressive conditional heteroskedasticity (ARCH) and generalised ARCH (GARCH) models that take into account the time-varying variances of time series data [suitable surveys of ARCH modelling may be found in Bollerslev, et al. (1992), Bera and Higgins (1993) and Pagan (1996)]. More recently, the univariate GARCH model has been extended to the multivariate GARCH (MGARCH) case, with the recognition that MGARCH models are potentially useful developments regarding the parameterization of conditional cross-moments. Although the MGARCH methodology has 
been used extensively in modelling financial time series [see, for instance, Dunne (1999), Tai (2000), Brooks et al. (2002) and Tse and Tsui (2002)], to the authors' knowledge a detailed study of the application of MGARCH to electricity markets has not been undertaken. Since this approach captures the effect on current volatility of both own innovation and lagged volatility shocks emanating from within a given market and cross innovation and volatility spillovers from interconnected markets it permits a greater understanding of volatility and volatility persistence in these interconnected markets. It is within the context of this limited empirical work that the present study is undertaken.

Accordingly, the purpose of this paper is to investigate the price and price volatility interrelationships between the Australian regional electricity markets. If there is a lack of significant interrelationships between regions then doubt may then be cast on the ability of the NEM to overcome the exercise of regional market power as its primary objective, and on its capacity to foster a nationally integrated and efficient electricity market. The paper itself is divided into four sections. The second section explains the data employed in the analysis and presents some brief summary statistics. The third section discusses the methodology employed. The results are dealt with in the fourth section. The paper ends with some brief concluding remarks.

\section{Data and summary statistics}

The data employed in the study are daily spot prices for electricity encompassing the period from the date of commencement of the National Electricity Market (NEM) on 13 December 1998 to 30 June 2001. The sample period is chosen on the basis that it represents a continuous series of data since the establishment of the Australian National Electricity Market (NEM). All price data is obtained from the National Electricity Market Management Company (NEMMCO) originally on a half-hourly basis representing 48 trading intervals in each 24-hour period. Following Lucia and Schwartz (2001) a series of daily arithmetic means is drawn from the trading interval data. Although such treatment entails the loss of at least some 'news' impounded in the more frequent trading interval data, daily averages play an important role in electricity markets, particularly in the case of financial contracts. For example, the electricity strips traded on the Sydney Futures Exchange (SFE) are settled against the arithmetic mean of half hourly spot prices. Moreover, De Vany and Walls (1999a; 1999b) and Robinson (2000) both employ daily spot prices in their respective analyses of the western United States and United Kingdom spot electricity markets. 


\section{$<$ TABLE 1 HERE $>$}

Table 1 presents the summary of descriptive statistics of the daily spot prices for the five electricity markets. Samples means, medians, maximums, minimums, standard deviations, skewness, kurtosis and the Jacque-Bera statistic and $p$-value are reported. Between 13 December 1998 and 30 June 2001, the highest spot prices are in Queensland (QLD) and South Australia (SA) averaging \$42.71 and \$57.92 per megawatt-hour, respectively. The lowest spot prices are in New South Wales (NSW) and the Snowy Mountains Hydroelectric Scheme (SNO) with \$33.02 and \$32.56, respectively. The standard deviations for the spot electricity range from \$27.84 (Snowy Mountains Hydroelectric Scheme) to \$92.15 (South Australia). Of the five markets, New South Wales (NSW) and the Snowy Mountains Hydroelectric Scheme (SNO) are the least volatile, while Queensland (QLD) and South Australia (SA) are the most volatile. The value of the coefficient of variation (standard deviation divided by the mean price) measures the degree of variation in spot price relative to the mean spot price. Relative to the average spot price, New South Wales (NSW) and the Snowy Mountains Hydroelectric Scheme (SNO) are less variable than South Australia (SA) and Victoria (VIC). A visual perspective on the volatility of spot prices can be gained from the plots of daily spot prices for each series in Figure 1.

\section{$<$ FIGURE 1 HERE $>$}

The distributional properties of the spot price series generally appear non-normal. All of the spot electricity markets are positively skewed and since the kurtosis, or degree of excess, in all of these electricity markets exceeds three, a leptokurtic distribution is indicated. The calculated Jarque-Bera statistic and corresponding $p$-value in Table 1 is used to test the null hypotheses that the daily distribution of spot prices is normally distributed. All $p$-values are smaller than the .01 level of significance suggesting the null hypothesis can be rejected. These daily spot prices are then not well approximated by the normal distribution. Lastly, each price series is tested for the presence of a unit root using the Augmented Dickey-Fuller (ADF) test. Contrary to previous empirical work De Vany and Walls (1999a; 1999b), which found that spot electricity prices contain a unit root, this study concurs with Lucia and Schwartz (2001) that electricity prices are stationary. 


\section{Methodology}

A MGARCH model is developed to examine the joint processes relating the daily spot prices for the five regional electricity markets. The following conditional expected price equation accommodates each market's own prices and the prices of other markets lagged one period.

$$
P_{t}=\alpha+A P_{t-1}+\varepsilon_{t}
$$

where $P_{t}$ is an $n \times 1$ vector of daily prices at time $t$ for each market and $\left.\varepsilon_{t}\right|_{t-1} \sim N\left(0, H_{t}\right)$. The $n \times 1$ vector of random errors, $\varepsilon_{t}$ is the innovation for each market at time $t$ with its corresponding $n \times n$ conditional variance-covariance matrix, $H_{t}$. The market information available at time $t$ - 1 is represented by the information set $I_{t-1}$. The $n \times 1$ vector, $\alpha$, represent long-term drift coefficients. The elements $a_{i j}$ of the matrix $A$ are the degree of mean spillover effect across markets, or put differently, the current prices in market $i$ that can be used to predict future prices (one day in advance) in market $j$. The estimates of the elements of the matrix, $A$, can provide measures of the significance of the own and cross-mean spillovers. This multivariate structure then enables the measurement of the effects of the innovations in the mean spot prices of one series on its own lagged prices and those of the lagged prices of other markets.

Engle and Kroner (1995) present various MGARCH models with variations to the conditional variance-covariance matrix of equations. For the purposes of the following analysis, the BEKK (Baba, Engle, Kraft and Kroner) model is employed, whereby the variance-covariance matrix of equations depends on the squares and cross products of innovation $\varepsilon_{t}$ and volatility $H_{t}$ for each market lagged one period. One important feature of this specification is that it builds in sufficient generality, allowing the conditional variances and covariances of the electricity markets to influence each other, and, at the same time, does not require the estimation of a large number of parameters (Karolyi 1995). The model also ensures the condition of a positive semi-definite conditional variance-covariance matrix in the optimisation process, and is a necessary condition for the estimated variances to be zero or positive. The BEKK parameterisation for the MGARCH model is written as:

$$
H_{t}=B^{\prime} B+C^{\prime} \varepsilon_{t} \varepsilon_{t-1} C+G^{\prime} H_{t-1} G
$$

where $b_{i j}$ are elements of an $n \times n$ symmetric matrix of constants $B$, the elements $c_{i j}$ of the symmetric $n \times n$ matrix $C$ measure the degree of innovation from market $i$ to market $j$, and the 
elements $g_{i j}$ of the symmetric $n \times n$ matrix $G$ indicate the persistence in conditional volatility between market $i$ and market $j$. This can be expressed for the bivariate case of the BEKK as:

$$
\left[\begin{array}{l}
H_{11 t} H_{12 t} \\
H_{21 t} H_{22 t}
\end{array}\right]=B^{\prime} B+\left[\begin{array}{l}
c_{11} c_{12} \\
c_{21} c_{22}
\end{array}\right]^{\prime}\left[\begin{array}{c}
\varepsilon_{1 t-1}^{2} \varepsilon_{1 t-1} \varepsilon_{2 t-1} \\
\varepsilon_{2 t-1} \varepsilon_{1 t-1} \varepsilon_{2 t-1}^{2}
\end{array}\right]\left[\begin{array}{l}
c_{11} c_{12} \\
c_{21} c_{22}
\end{array}\right]+\left[\begin{array}{l}
g_{11} g_{12} \\
g_{21} g_{22}
\end{array}\right]^{\prime}\left[\begin{array}{l}
H_{11 t-1} H_{12 t-1} \\
H_{21 t-1} H_{22 t-1}
\end{array}\right]\left[\begin{array}{l}
g_{11} g_{12} \\
g_{21} g_{22}
\end{array}\right]
$$

In this parameterization, the parameters $b_{i j}, c_{i j}$ and $g_{i j}$ cannot be interpreted on an individual basis: "instead, the functions of the parameters which form the intercept terms and the coefficients of the lagged variance, covariance, and error terms that appear are of interest” (Kearney and Patton 2000: 36). With the assumption that the random errors are normally distributed, the log-likelihood function for the MGARCH model is:

$$
L(\theta)=-\frac{T n}{2}+\ln (2 \pi)-\frac{1}{2} \sum_{t=1}^{T}\left(\ln \left|H_{t}\right|+\varepsilon_{t}^{\prime}\left|H_{t}^{-1}\right| \varepsilon_{t}\right)
$$

where $T$ is the number of observations, $n$ is the number of markets, $\theta$ is the vector of parameters to be estimated, and all other variables are as previously defined. The BHHH (Berndt, Hall, Hall and Hausman) algorithm is used to produce the maximum likelihood parameter estimates and their corresponding asymptotic standard errors. Overall, the proposed model has twenty-five parameters in the mean equations, excluding the five constant (intercept) parameters, and twenty-five intercept, twenty-five white noise and twenty-five volatility parameters in the estimation of the covariance process, giving one hundred and five parameters in total.

Lastly, the Ljung-Box $Q$ statistic is used to test for independence of higher relationships as manifested in volatility clustering by the MGARCH model [Huang and Yang 2000:329]. This statistic is given by:

$$
Q=T(T+2) \sum_{j=1}^{p}(T-j)^{-1} r^{2}(j)
$$

where $r(j)$ is the sample autocorrelation at lag $j$ calculated from the noise terms and $T$ is the number of observations. $Q$ is asymptotically distributed as $\chi^{2}$ with $(p-k)$ degrees of freedom and $k$ is the number of explanatory variables. This test statistic is used to test the null hypothesis that the model is independent of the higher order volatility relationships. 


\section{Empirical results}

The estimated coefficients and standard errors for the conditional mean price equations are presented in Table 2. All estimations are made using the S-PLUS ${ }^{\circledR}$ statistical software with the GARCH add-on module. For the five electricity spot markets only QLD and SNO exhibit a significant own mean spillover from their own lagged electricity price. In both cases, the mean spillovers are positive. For example, in QLD a \$1.00 per megawatt-hour increase in its own spot price will Granger cause an increase of $\$ 0.51$ per megawatt-hour in its price over the next day. Likewise, a \$1.00 per megawatt-hour increase in the SNO lagged spot price will Granger cause a \$0.70 increase the next day. Importantly, there are no significant lagged mean spillovers from any of the spot markets to any of the other markets. This indicates that on average short-run price changes in any of the five Australian spot markets are not associated with price changes in any of the other spot electricity markets, despite the connectivity offered by the NEM.

\section{$<$ TABLE 2 HERE $>$}

The conditional variance covariance equations incorporated in the paper's multivariate GARCH methodology effectively capture the volatility and cross volatility spillovers among the five spot electricity markets. These have not been considered by previous studies. Table 3 presents the estimated coefficients for the variance covariance matrix of equations. These quantify the effects of the lagged own and cross innovations and lagged own and cross volatility persistence on the own and cross volatility of the electricity markets. The coefficients of the variance covariance equations are generally significant for own and cross innovations and significant for own and cross volatility spillovers to the individual prices for all electricity markets, indicating the presence of strong ARCH and GARCH effects. In evidence, 68 percent (seventeen out of twenty-five) of the estimated ARCH coefficients and 84 percent (twenty-one out of twenty-five) of the estimated GARCH coefficients are significant at the .10 level or lower.

\section{$<$ TABLE 3 HERE $>$}

Own-innovation spillovers in all the electricity markets are large and significant indicating the presence of strong ARCH effects. The own-innovation spillover effects range from 0.0915 in VIC to 0.1046 in SNO. In terms of cross-innovation effects in the electricity markets, past innovations in most markets exert an influence on the remaining electricity markets. For example, in the case of VIC cross innovation in the NSW, SA and SNO markets are 
significant, of which NSW has the largest effect. The exception to the presence of strong cross innovation effects is QLD. No cross innovations outside of QLD influence that market, and the QLD market does influence any of the other electricity markets, at least over the period in question. This is consistent with the role of QLD in the NEM in that it has only limited direct connectivity with just one other regional market (NSW).

In the GARCH set of parameters, eighty-four percent of the estimated coefficients are significant. For NSW the lagged volatility spillover effects range from 0.7839 for SA to 0.8412 for QLD. This means that the past volatility shocks in QLD have a greater effect on the future NSW volatility over time than the past volatility shocks in other spot markets. Conversely, in QLD the post volatility shocks range from 0.65212 for SA to 0.8413 for SNO. In terms of cross-volatility for the GARCH parameters, the most influential markets would appear to be NSW and SNO. That is, past volatility shocks in the NSW and SNO electricity spot markets have the greatest effect on the future volatility in the three remaining electricity markets. The sum of the ARCH and GARCH coefficients measures the overall persistence in each market's own and cross conditional volatility. All five electricity markets exhibit strong own persistence volatility ranging from 0.9032 for NSW to 0.9143 for SNO. Thus, SNO has a lead-persistence volatility spillover effect on the remaining electricity markets. The crossvolatility persistence spillover effects range from 0.7751 for SA 0.9409 for QLD.

\section{$<$ TABLE 4 HERE $>$}

Finally, the Ljung-Box (LB) $Q$ statistics for the standardised residuals in Table 4 reveal that all electricity spot markets are highly significant (all have $p$-values of less than .01) with the exception of SNO (a $p$-value of 0.1166). Significance of the Ljung-Box (LB) $Q$ statistics for the electricity spot price series indicates linear dependences due to the strong conditional heteroskedasticity. These Ljung-Box statistics suggest a strong linear dependence in four out of the five electricity spot markets estimated by the MGARCH model.

\section{Conclusions and policy implications}

This paper highlights the transmission of prices and price volatility among five Australian electricity spot markets during the period 1998 to 2001. All of these spot markets are member jurisdictions of the recently established National Electricity Market (NEM). At the outset, unit root tests confirm that Australian electricity spot prices are stationary. A multivariate generalised autoregressive conditional heteroskedasticity (MGARCH) model is then used to identify the source and magnitude of spillovers. The estimated coefficients from the 
conditional mean price equations indicate that despite the presence of a national market for electricity, the regional electricity spot markets are not integrated. In fact, only two of the five markets exhibit a significant own mean spillover. This also would suggest, for the most part, that Australian spot electricity prices could not be usefully forecasted using lagged price information from either each market itself or from other markets in the national market. However, own-volatility and cross-volatility spillovers are significant for nearly all markets, indicating the presence of strong ARCH and GARCH effects. Conventionally, this is used to indicate that markets are not efficient. Strong own and cross-persistent volatility are also evident in all Australian electricity markets. This indicates that while the limited nature of the interconnectors between the separate regional markets prevents full integration, shocks or innovations in particular markets still exert an influence on price volatility. Thus, during periods of abnormally high demand for example, the NEM may be at least partially offsetting the ability of regional participants to exert market power.

Nonetheless, the results mainly indicate the inability of the existing network of interconnectors to create a substantially integrated national electricity market and that, for the most part, the sizeable differences in spot prices between most of the regions will remain, at least in the short term. This provides validation for new regional interconnectors currently under construction and those that are proposed, and the anticipated inclusion of Tasmania as a sixth region in the NEM. As a general rule, the less direct the interconnection between regions, the less significant the cross-innovation and volatility spillover effects between these regions. This suggests that main determinant of the interaction between regional electricity markets is geographical proximity and the number and size of interconnectors. Accordingly, it may be unreasonable to expect that prices in electricity markets that are geographically isolated market will ever become fully integrated with 'core' or geographically proximate markets.

The results also indicate that volatility innovations or shocks in all markets persist over time and that in all markets this persistence is more marked for own-innovations or shocks than cross-innovations or shocks. This persistence captures the propensity of price changes of like magnitude to cluster in time and explains, at least in part, the nonnormality and nonstability of Australian electricity spot prices. Together, these indicate that neither the NEM nor the regional markets are efficiently pricing electricity and that changes to the market mechanism may be necessary. It may also reinforce calls for the privatisation of some electricity market participants to improve competition, given that the overwhelming majority of these remain under public sector control. 
Of course, the full nature of the price and volatility interrelationships between these separate markets could be either under or overstated by misspecification in the data, all of which suggest future avenues for research. One possibility is that by averaging the half-hourly prices throughout the day, the speed at which innovations in one market influence another could be understated. For instance, with the data as specified the most rapid innovation allowed in this study is a day, whereas in reality innovations in some markets may affect others within just a few hours. Similarly, there has been no attempt to separate the differing conditions expected between peak and off-peak prices. For example, De Vany and Walls (1999) found that there were essentially no price differentials between trading points in offpeak periods because they were less constrained by limitations in the transmission system. Another possibility is that the occurrence of time-dependent conditional heteroskedasticity could be due to an increased volume of trading and/or variability of prices following the arrival of new information into the market. It is well known that financial markets, for instance, can still be efficient but exhibit GARCH effects in price changes if information arrives at uneven intervals. One future application of modelling would then include, say, demand volume as a measure of the amount of information that flows into the electricity market. This would provide definitive proof of whether the GARCH effects are really evidence of market inefficiency, or the result of the irregular flow of market information.

Research into Australian electricity markets could be extended in a number of other ways. One useful extension would be to examine each of the five electricity markets individually and in more detail. For example, while the sample for this study is determined by the period of tenure of the National Electricity Market (NEM) wholesale electricity spot markets in the separate regions pre-date this by several years. An examination of the connection between the long-standing electricity spot markets in NSW and Victoria would be particularly useful. Another suggestion concerns the electricity strip contracts offered by the Sydney Futures Exchange (2002) on several of Australia's NEM jurisdictions. An examination of the relationships between Australian spot and derivative electricity prices would then be interesting.

\section{References}

Australian Competition and Consumer Commission (ACCC), 2000. Infrastructure Industries: Energy. Commonwealth of Australia, Canberra.

Bera, A.K., Higgins, M.L., 1993. ARCH models: Properties, estimation and testing. J. Econ. Surveys. 7, 305366. 
Bollerslev, T., Chou, R.Y., Kroner, K.F., 1992. ARCH modeling in finance: A review of the theory and empirical evidence. J. Economet. 52, 5-59.

Brennan, D., Melanie, J., 1998. Market power in the Australian power market. Energy Econ. 20, 121-133.

Brooks, C., Henry, O.T., Persand, G., 2002. The effects of asymmetries on optimal hedge ratios. J. Bus. 75, 333352.

De Vany, A.S., Walls, W.D., 1999a. Cointegration analysis of spot electricity prices: Insights on transmission efficiency in the western US. Energy Econ. 21, 435-448.

De Vany, A.S., Walls, W.D., 1999b. Price dynamics in a network of decentralized power markets. J. Regulatory Econ. 15, 123-140.

Dickson, A., Warr, S., 2000. Profile of the Australian Electricity Industry. Australian Bureau of Agricultural and Resource Economics (ABARE) Research Report No. 2000.7, Canberra.

Dunne, P.G., 1999. Size and book-to market factors in a multivariate GARCH-in-mean asset pricing application. Int. Rev. Fin. Analysis. 8, 35-52.

Engle, R.F., Kroner, K.F., 1995. Multivariate simultaneous generalized ARCH. Economet. Theory. 11, $122-150$.

Huang, B.N., Yang, C.W., 2000. The impact of financial liberalization on stock price volatility in emerging markets. J. Comp. Econ. 28, 321-339.

International Energy Agency (IEA), 2001. Energy Policies of IEA Countries: Australia 2001 Review. Organisation for Economic Cooperation and Development, Paris.

Joskow, P.L., Kahn, E., 2001. A quantitative analysis of pricing behaviour in California's wholesale electricity market during summer 2000. Energy J. 23, 1-35.

Karolyi, G.A., 1995. A multivariate GARCH model of international transmissions of stock returns and volatility: The case of the United States and Canada. J. Bus. Econ. Stat. 13, 11-25.

Kearney, C., Patton, A.J., 2000. Multivariate GARCH modeling of exchange rate volatility transmission in the European monetary system. Fin. Rev. 41, 29-48.

Lucia, J.J., Schwartz, E.S., 2001. Electricity Prices and Power Derivatives: Evidence for the Nordic Power Exchange. University of California Los Angeles Working Paper, Los Angeles.

National Electricity Market Management Company Limited (NEMMCO), 2001. An Introduction to Australia’s National Electricity Market. NEMMCO, Melbourne.

National Electricity Market Management Company Limited (NEMMCO), 2002. WWW site: $<$ http://www.nemmco.com.au/>. Accessed December 2002.

Pagan, A., 1996. The econometrics of financial markets. J. Fin. 3, 15-102.

Robinson, T., 2000. Electricity pool series: A case study in non-linear time series modeling. App. Econ. 32, 527532.

Robinson, T., Baniak, A., 2002. The volatility of prices in the English and Welsh electricity pool. App. Econ. 34, 1487-1495.

Tai, C.S., 2000. Time-varying market, interest rate and exchange rate risk premia in the US commercial bank stock returns. J. Mult. Fin. Mgmt. 10, 397-420.

Tse, Y.K., Tsui, A.K.C., 2002. A multivariate generalised autoregressive conditional heteroscedasticity model with time-varying correlations. J. Bus. Econ. Stat. 20, 351-362.

Wilson, R., 2002. Architecture of power markets, Economet. 70, 1299-1340. 
Table 1

Summary statistics of spot prices in five Australian electricity markets

\begin{tabular}{lrrrrr}
\hline & NSW & \multicolumn{1}{c}{ QLD } & \multicolumn{1}{c}{ SA } & \multicolumn{1}{c}{ SNO } & \multicolumn{1}{c}{ VIC } \\
\hline Mean & 33.0244 & 42.7055 & 57.9171 & 32.5624 & 35.5077 \\
Median & 26.4246 & 30.4117 & 38.9352 & 26.5121 & 25.3052 \\
Maximum & 388.2060 & 1175.5260 & 1152.5750 & 366.1698 & 1014.6010 \\
Minimum & 11.6533 & 13.2871 & 11.5225 & 11.0992 & 4.9785 \\
Std. Dev. & 29.6043 & 60.8140 & 92.1549 & 27.8366 & 58.5227 \\
CV & 0.8964 & 1.4240 & 1.5912 & 0.8549 & 1.6482 \\
Skewness & 6.8871 & 11.6290 & 7.6208 & 6.8653 & 12.0381 \\
Kurtosis & 66.2028 & 187.4572 & 69.3994 & 69.0835 & 179.8255 \\
Jarque-Bera & 127447 & 1052805 & 141362 & 138754 & 970003 \\
JB probability & 0.0000 & 0.0000 & 0.0000 & 0.0000 & 0.0000 \\
ADF test & -5.5564 & -7.6672 & -8.8834 & -6.1225 & -8.2235 \\
\hline
\end{tabular}

Notes: NSW - New South Wales, QLD - Queensland, SA - South Australia, SNO - Snowy Mountains Hydroelectric Scheme, VIC - Victoria. ADF - Augmented Dickey-Fuller test statistics; CV - coefficient of variation; JB - Jarque-Bera. Hypothesis for ADF test: $\mathrm{H}_{0}$ : unit root (non-stationary), $\mathrm{H}_{1}$ : no unit root (stationary). The lag orders in the ADF equations are determined by the significance of the coefficient for the lagged terms. Only intercepts are included. Critical values are -3.4420 at.01, -2.8659 at .05 and -2.5691 at the .10 levels.

Figure 1

Daily spot electricity prices for five Australian markets, 13/12/1998 - 30/6/2001
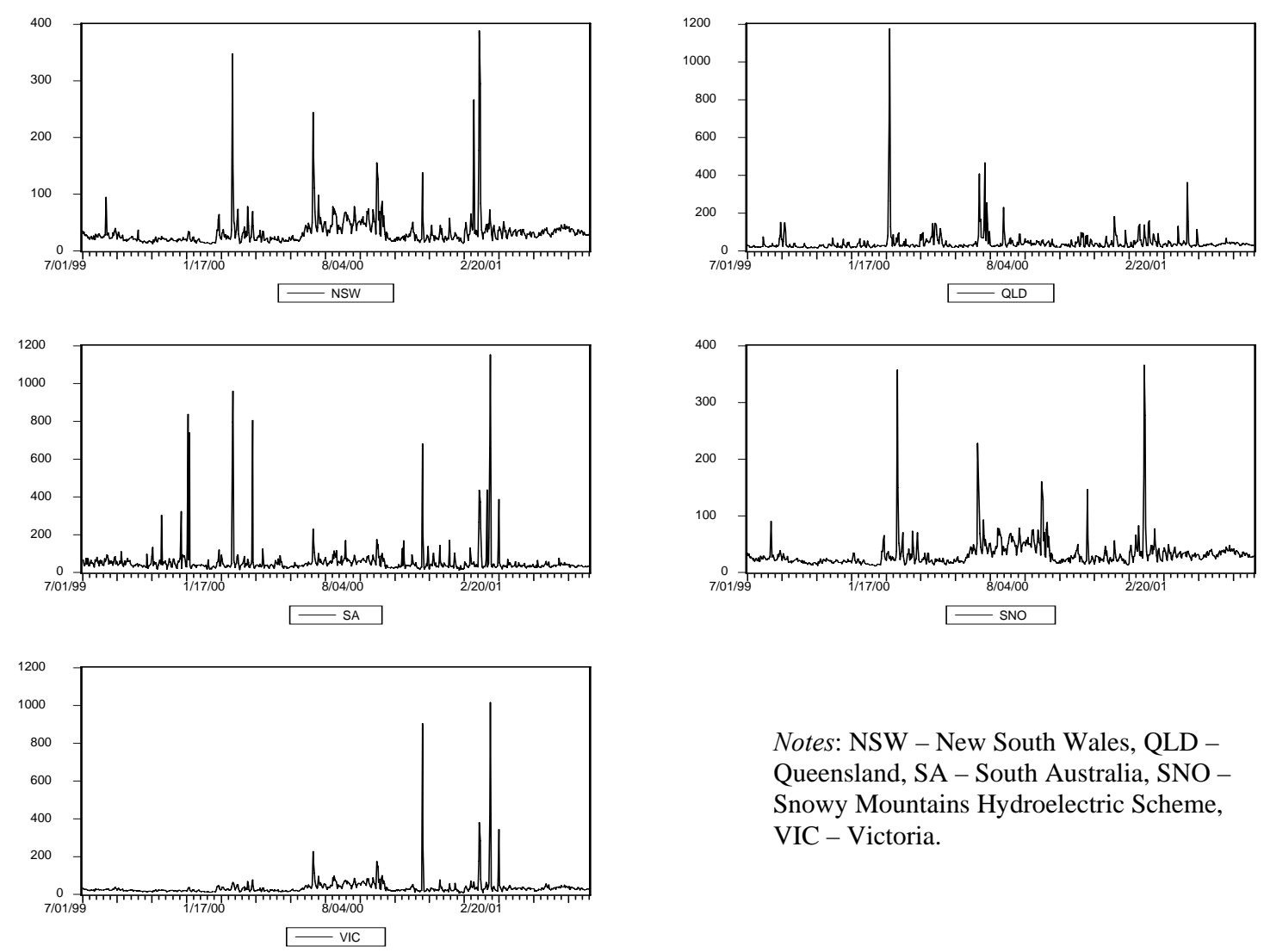

Notes: NSW - New South Wales, QLD Queensland, SA - South Australia, SNO Snowy Mountains Hydroelectric Scheme, VIC - Victoria. 
Table 2

Estimated coefficients for conditional mean price equations

\begin{tabular}{|c|c|c|c|c|c|c|c|c|c|c|}
\hline & \multicolumn{2}{|c|}{$\operatorname{NSW}(i=1)$} & \multicolumn{2}{|c|}{ QLD $(i=2)$} & \multicolumn{2}{|c|}{$\mathrm{SA}(i=3)$} & \multicolumn{2}{|c|}{$\operatorname{SNO}(i=4)$} & \multicolumn{2}{|c|}{$\operatorname{VIC~}(i=5)$} \\
\hline & $\begin{array}{c}\text { Estimated } \\
\text { coefficient }\end{array}$ & $\begin{array}{l}\text { Standard } \\
\text { error }\end{array}$ & $\begin{array}{c}\text { Estimated } \\
\text { coefficient }\end{array}$ & $\begin{array}{l}\text { Standard } \\
\text { error }\end{array}$ & $\begin{array}{l}\text { Estimated } \\
\text { coefficient }\end{array}$ & $\begin{array}{l}\text { Standard } \\
\text { error }\end{array}$ & $\begin{array}{c}\text { Estimated } \\
\text { coefficient }\end{array}$ & $\begin{array}{l}\text { Standard } \\
\text { error }\end{array}$ & $\begin{array}{c}\text { Estimated } \\
\text { coefficient }\end{array}$ & $\begin{array}{l}\text { Standard } \\
\text { error }\end{array}$ \\
\hline CONS. & ** 12.8966 & 6.8610 & *16.0313 & 11.3500 & 16.18667 & 18.8600 & ${ }^{* *} 12.2740$ & 5.5630 & 11.2951 & 20.7400 \\
\hline$a_{i 1}$ & 0.0497 & 0.7556 & -0.0135 & 0.0951 & -0.0237 & 0.0844 & $\begin{array}{l}+5977 \\
+\quad 0.5977\end{array}$ & 0.8215 & 0.0248 & 0.1749 \\
\hline$a_{i 2}$ & 0.0410 & 2.0470 & ${ }^{* * *} 0.5118$ & 0.1291 & -0.0658 & 0.2296 & 0.2046 & 2.2010 & 0.0321 & 0.4654 \\
\hline$a_{i 3}$ & -0.1159 & 5.5800 & -0.0529 & 0.3520 & 0.2493 & 0.1946 & 1.0097 & 5.6880 & -0.0344 & 0.6905 \\
\hline$a_{i 4}$ & -0.0548 & 0.2984 & -0.0131 & 0.0778 & -0.0265 & 0.0557 & ${ }^{* *} 0.7001$ & 0.3884 & 0.0318 & 0.1425 \\
\hline$a_{i 5}$ & -0.1641 & 4.0450 & -0.0049 & 0.3352 & 0.0310 & 0.1113 & 0.4664 & 4.0390 & 0.3102 & 0.5095 \\
\hline
\end{tabular}

Notes: NSW - New South Wales, QLD - Queensland, SA - South Australia, SNO - Snowy Mountains Hydroelectric Scheme, VIC - Victoria. Asterisks indicate significance at ${ }^{*}-0.10,{ }^{* *}-0.05,{ }^{* * *}-0.01$ level

Table 3

Estimated coefficients for variance covariance equations

\begin{tabular}{|c|c|c|c|c|c|c|c|c|c|c|}
\hline & \multicolumn{2}{|c|}{$\mathrm{NSW}(j=1)$} & \multicolumn{2}{|c|}{$\mathrm{QLD}(j=2)$} & \multicolumn{2}{|c|}{$\mathrm{SA}(j=3)$} & \multicolumn{2}{|c|}{$\operatorname{SNO}(j=4)$} & \multicolumn{2}{|c|}{ VIC $(j=5)$} \\
\hline & $\begin{array}{c}\text { Estimated } \\
\text { coefficient }\end{array}$ & $\begin{array}{c}\text { Standard } \\
\text { error }\end{array}$ & $\begin{array}{c}\text { Estimated } \\
\text { coefficient }\end{array}$ & $\begin{array}{l}\text { Standard } \\
\text { error }\end{array}$ & $\begin{array}{c}\text { Estimated } \\
\text { coefficient }\end{array}$ & $\begin{array}{c}\text { Standard } \\
\text { error }\end{array}$ & $\begin{array}{c}\text { Estimated } \\
\text { coefficient }\end{array}$ & $\begin{array}{c}\text { Standard } \\
\text { error }\end{array}$ & $\begin{array}{c}\text { Estimated } \\
\text { coefficient }\end{array}$ & $\begin{array}{c}\text { Standard } \\
\text { error }\end{array}$ \\
\hline$b_{1 \mathrm{j}}$ & ${ }^{* * *} 80.2657$ & 16.6300 & 18.7260 & 59.5500 & 120.9672 & 124.3000 & ${ }^{* * *} 71.3986$ & 12.8500 & 75.8586 & 78.8900 \\
\hline$b_{2 \mathrm{j}}$ & 18.7260 & 59.5500 & *336.6956 & 99.0900 & 41.1680 & 332.7000 & 17.1266 & 66.2000 & 31.8362 & 285.4000 \\
\hline$b_{3 \mathrm{j}}$ & 120.9672 & 124.3000 & 41.1680 & 332.7000 & ${ }^{* *} 635.0478$ & 353.4000 & * 120.0339 & 88.1800 & 229.8638 & 219.7000 \\
\hline$b_{4 \mathrm{j}}$ & ${ }^{* * *} 71.3986$ & 12.8500 & 17.1266 & 66.2000 & ${ }^{*} 120.0339$ & 88.1800 & **67.6679 & 11.7500 & ${ }^{* *} 75.3265$ & 41.9500 \\
\hline$b_{5 j}$ & 75.8586 & 78.8900 & 31.8362 & 285.4000 & 229.8638 & 219.7000 & ${ }^{* *} 75.3265$ & 41.9500 & 295.1421 & 62.2100 \\
\hline$c_{1 \mathrm{j}}$ & ${ }^{* * *} 0.0985$ & 0.0140 & 0.0997 & 0.1735 & ${ }^{* * *} 0.0989$ & 0.0278 & ${ }^{* * *} 0.1013$ & 0.0043 & ${ }^{* * *} 0.0992$ & 0.0221 \\
\hline$c_{2 \mathrm{j}}$ & 0.0997 & 0.1735 & *0.1008 & 0.0198 & 0.1232 & 0.2944 & 0.0993 & 0.2777 & 0.0834 & 0.3979 \\
\hline$c_{3 \mathrm{j}}$ & ${ }^{* * *} 0.0989$ & 0.0278 & 0.1232 & 0.2944 & ${ }^{* * *} 0.0991$ & 0.0216 & *** 0.1021 & 0.0126 & ${ }^{* * * *} 0.0937$ & 0.0211 \\
\hline$c_{4 \mathrm{j}}$ & ${ }^{* * *} 0.1013$ & 0.0043 & 0.0993 & 0.2777 & ${ }^{* * *} 0.1021$ & 0.0126 & ${ }^{* * *} 0.1046$ & 0.0105 & ${ }^{* * *} 0.0978$ & 0.0175 \\
\hline$c_{5 j}$ & ${ }^{* * *} 0.0992$ & 0.0221 & 0.0834 & 0.3979 & ${ }^{* * *} 0.0937$ & 0.0211 & ${ }^{* * *} 0.0978$ & 0.0175 & **0.0915 & 0.0249 \\
\hline$g_{1 \mathrm{j}}$ & ${ }^{* * *} 0.8047$ & 0.0133 & ${ }^{* * *} 0.8412$ & 0.3192 & ${ }^{* * *} 0.7839$ & 0.0959 & ${ }^{* * *} 0.8080$ & 0.0001 & ${ }^{* * *} 0.8034$ & 0.0447 \\
\hline$g_{2 j}$ & ${ }^{* * *} 0.8412$ & 0.3192 & ${ }^{* * *} 0.8051$ & 0.0416 & 0.6520 & 1.3560 & ${ }^{* *} 0.8413$ & 0.4615 & 0.8234 & 1.0580 \\
\hline$g_{3 j}$ & ${ }^{* * *} 0.7839$ & 0.0959 & 0.6520 & 1.3560 & ${ }^{* * *} 0.8107$ & 0.0309 & ${ }^{* * *} 0.7868$ & 0.0961 & ${ }^{* * *} 0.8148$ & 0.0263 \\
\hline$g_{4 \mathrm{j}}$ & ${ }^{* * *} 0.8080$ & 0.0001 & ${ }^{* *} 0.8413$ & 0.4615 & ${ }^{* * *} 0.7868$ & 0.0961 & ${ }^{* * *} 0.8098$ & 0.0128 & ${ }^{* * *} 0.8056$ & 0.0316 \\
\hline$g_{5 \mathrm{j}}$ & ${ }^{* * *} 0.8034$ & 0.0447 & 0.8234 & 1.0580 & ${ }^{* * *} 0.8148$ & 0.0263 & ${ }^{* * *} 0.8056$ & 0.0316 & ${ }^{* * *} 0.8119$ & 0.0233 \\
\hline
\end{tabular}

Notes: NSW - New South Wales, QLD - Queensland, SA - South Australia, SNO - Snowy Mountains Hydroelectric Scheme, VIC - Victoria. Asterisks indicate significance at ${ }^{*}-0.10,{ }^{* *}-0.05,{ }^{* * *}-0.01$ level

Table 4

Ljung-Box tests for standardized residuals

\begin{tabular}{lrrrrr}
\hline & NSW & \multicolumn{1}{c}{ QLD } & \multicolumn{1}{c}{ SA } & \multicolumn{1}{c}{ SNO } & \multicolumn{1}{c}{ VIC } \\
\hline Statistic & 27.0100 & 32.4600 & 44.7000 & 17.9700 & 50.8700 \\
$p$-value & 0.0077 & 0.0012 & 0.0000 & 0.1166 & 0.0000 \\
\hline
\end{tabular}

